\title{
Learners' Performance in Doing Task with and without Teacher's Presence
}

\author{
Massoud Rahimpour (Corresponding author) \\ The University of Tabriz and The University of Queensland \\ E-mail: rahimpour2011@gmail.com \\ Elham Zakeri \\ English Department, Faculty of Persian Literature and Foreign Languages \\ The University of Tabriz \\ E-mail:elham_zakri2007@yahoo.com
}

Received: October 27, $2010 \quad$ Accepted: November 10, $2010 \quad$ doi:10.5539/elt.v4n2p66

\begin{abstract}
Recently task-based language teaching has attracted many researchers', testers' and syllabus designers' attention and consequently a lot of studies are carried out in this field. This study was conducted in the task-based realm too. The main purpose of this study was to investigate the effect of teacher's presence on learners' performance in doing task with and without teacher presence. The participants of this were forty (40) EFL intermediate male and female English learners who were chosen randomly. The results of statistical analysis of the collected data revealed that teacher's presence affected the participants' oral performance in terms of fluency but not their accuracy and complexity. The findings of this study have implications for language teaching, testing and syllabus design.
\end{abstract}

Keywords: Task-based language teaching, Task condition, Communicative tasks, Fluency, Accuracy, Complexity

\section{Introduction}

Task-based language teaching is argued to provide favorable conditions for learning, it focuses on meaning, it enhances learning the second language and this is why it is practiced worldwide although it is stated that there isn't pure practical manifestations of this method yet (Long \& Crooks, 1998). In task-based language teaching and learning the main unit of analysis is task and there have been different studies to examine its role in Second Language Learning (SLL) (Gilabert, 2005, 2007; Rahimpour,1995,1997, 2001, 2002, 2005,2007, 2008, 2010; Robinson, 1995, 2001, 2005) to name a few. A central issue in TBLT deals with the impact of task conditions on L2 learner's performance. There have been some studies investigating this effect but there is still so much work to be done. (Rahimpour, 2010; Bygate, 1996; Yule, et al., 1992).The aim of this paper is thus to investigate teacher's presence as a task condition on learners' performance in terms of accuracy, fluency and complexity.

\section{Literature Review}

Skehan $(1996,1998)$ tries to separate learner's general goal, becoming more native-like in one's performance, into three specific areas: accuracy, fluency, and complexity. Skehan (1998) and Bygate (1996) propose a trade-off among these three factors of language performance. They believe that under different conditions, one of these elements might be fostered and different factors influence them. On the whole, we expect this trade-off factor in almost all the studies and it is an inevitable part of language performance.

Few studies have been done on task conditions. It might be because of the controversial definitions of task conditions proposed by different researchers. The definition used here is the circumstances under which the task is performed. The conditions can be discussed in terms of whether the interlocutors know each other, whether planning time is provided or not, whether learners get feedback during their performance, whether they are familiar with the interviewer if it is an oral task, whether it is an open or a closed task, whether the task is convergent or divergent, whether the interlocutors are equal or not in terms of power, etc. Task conditions are specified in terms of information flow in classroom participation (e.g. one versus two-way tasks) and in terms of the grouping of participants (e.g., same versus different gender) (Robinson, 2005).

In the current related literature about task-based language instruction, task difficulty and task complexity are the two factors which have been investigated by many researchers (Robinson, 1995, 2001; Rahimpour, 1997, 1999, 2007; Rahimpour \& Robinson \& Urwin, 1996). Task conditions have been investigated too (Rahimpour \& Harrington, 
1996; Rahimpour, 2010) but they need more exploration and attention.

Different researchers argue that learners have differences in their performance under different conditions. In this paper the condition is whether the teacher is present or absent while participants of the study tell a story. In a study done by Pica, Young, and Doughty (1987), they found many more examples of interactional exchange when the teacher was not present than elicited when present. In other words, students showed greater interaction in teacher's absence than in his/her presence.

In a study by Brady and Bedient (2003) the effect of increased teacher's presence was investigated on students' attitudes toward instruction and their performance. At the end, the students in the experimental group had positive attitudes toward the teacher because the teacher's responsiveness was appreciated by this group. Also, the teacher's presence led to a better completion of the course by these students.

In another study by Basturkmen (2003) the exchange patterns and structures in a small university discussion group were examined in absence and presence of a teacher. It was a discussion class for MBA students and it was video-taped. Students were engaged in a discussion and it was recorded until half of the class. Then the teacher unexpectedly joined them until the end of the class. The results didn't show any radical changes in the exchange patterns in teacher's presence. In fact, this paper calls for more research to see the effects of an authority on different aspects of language description and performance. Actually, this paper was the main impetus for the present study as the name was "what happens when the tutor walks in?".

Also, Williams (2001) conducted a study in which she found out that students do not focus on form unless the teacher is present, i.e. he/she listens to them. Actually she found out that learners rarely focus on form while performing communicative tasks and when they do so it is only when the teacher is in attendance. This is the case especially with high proficiency learners. They also pay more attention to the forms mentioned by the teacher. In other words, students are more accurate in teacher's presence.

Skehan and Foster (2001), proposing Limited Attentional Capacity Model, believe that different task aspects and conditions of task performance can affect learners' attention to the accuracy, fluency or complexity of their language and this involves a trade-off on these dimensions. In line with the above discussion, the following research question and research hypothesis were formulated.

\section{Method}

\subsection{Research Question}

What is the effect of teacher's presence on L2 learners' oral performance in terms of fluency, accuracy and complexity?

\subsection{Research Hypothesis}

Teacher's presence affects learners' attention which will consequently lead to more accurate, fluent and complex performance.

\subsection{Participants}

The participants of this study were 40 male and female Iranian learners of English .All of them were learning English as a foreign language in an institute in Tabriz. All of the students were chosen randomly from the intermediate level of the institute. All of them performed the same task.

\subsection{Instruments}

Actually, we wanted to include some sort of a real-world task for the study but due to the shortage of facilities we used a series of pictures which are a category of pedagogic tasks. In fact, it is very common to use picture stories for data elicitation among researchers and linguists. According to Skehan (1996) this task can be said to manifest some sort of relationship to the real world.

Among different types of pedagogic tasks, narrative tasks are the most frequent ones employed to elicit the learners' performance in task-based language literature (Foster and Skehan, 1996; Skehan and Foster, 1999; Rahimpour, 2010).

Therefore, after deciding to use a pedagogic task, and among them a narrative task, a task was chosen which was clear for the learners to understand and there was a logical order among the pictures. The task was not so easy, nor so difficult. The story was of everyday topics. It did not have any cultural misunderstandings. The picture stories used by Elder and Iwashita (2005) were replicated in this study as the means of data elicitation (See Appendix ).

\subsection{Variables of the Study}

In this study teacher's presence was our independent variable and the triadic components of performance namely 
accuracy, fluency and complexity were our dependent variables.

The participants' oral performance was evaluated in terms of accuracy, fluency, and complexity based on the measures that will be discussed below.

\subsection{Dependent variable measurements}

To measure accuracy, the number of error-free T-units is divided by the total number of T-units (Rahimpour, 1997, 1999, 2008).

Fluency was achieved by calculating the number of words per minute (Skehan and Foster, 1999).

The number of lexical or 'open class' words in a text (full verbs, nouns, adjectives, and adverbs ending in -ly) divided by total words multiplied by 100. (Rahimpour, 1997, 1999, 2008)

\subsection{Procedure}

To collect the data, each student was called from the class individually to perform the task. They were told that it was not a test and they were free to take part in the data collection procedure. Then, they were told what they were supposed to do.

The study was carried out under two different conditions. In the first condition, each participant was asked to tell the story in teacher's presence and their performance was recorded in the tape recorder. In the second condition, each participant was alone and they recorded their own voice. For each condition twenty participants were allocated. Everything was explained clearly to the participants of the study and all the stages of data collection were smoothly completed. In the second condition, after each participant left the room, the researcher checked that their voice was recorded. So we didn't have any data loss.

After finishing the data collection procedure, the recordings were transcribed carefully and coded for the analysis.

\section{Results}

Table 1 provides the descriptive statistics for accuracy, fluency and complexity of L2 learners' oral performance with and without teacher presence.

\section{Insert Table 1 Here}

As can be seen, participants of the second group, that is the ones performing without teacher's presence, have a higher mean $(0.665>0.633)$. But this difference in not statistically significant. In terms of fluency, the mean of participants with teacher presence is greater than the ones without teacher's presence $(13.46>7.857)$. Also, this difference is statistically significant. Considering complexity, participants produced a more complex language in teacher's presence (43.729>41.713). But this difference is not statistically significant.

Table 2 displays the results of Independent Samples t-test for accuracy, fluency and complexity of L2 learners' oral performance with and without teacher's presence.

Insert Table 2 Here

As the table 2 shows, since the significance level of t-test in case of accuracy and complexity are higher than 0.05 (significance level $\mathrm{p}<0.05$ ), teacher presence had no significant effect on accuracy and complexity of the oral performance of the participants. However, the results revealed that there was a significant difference in terms of fluency with and without teacher presence. The significant level of t-test for fluency equaled 0.003 and this value was lower than 0.05.It means that fluency of the learners was affected by teacher's presence. Therefore, our hypothesis stating that 'Teacher's presence will lead to greater fluency' is confirmed. But the research hypothesis is not confirmed in terms of accuracy and complexity.

Figure 1 shows the mean of accuracy of 12 learners' oral performance with and without teacher's presence. As mentioned before; the mean of accuracy with teacher presence is less than the mean of accuracy without teacher presence.

Insert Figure 1 Here

Figure 2 illustrates the mean of fluency of L2 learners' oral performance with and without teacher's presence. As the figure demonstrates, the mean of fluency with teacher's presence is greater than the mean of fluency without teacher's presence and this difference is statistically significant.

Insert Figure 2 Here

Figure 3 shows the mean of complexity of 12 learners' oral performance with and without teacher's presence. Although the mean of complexity in teacher's presence is greater than the mean of complexity in teacher's absence, 
this difference is not statistically significant regarding the result of t-test.

Insert figure 3 Here

\section{Discussion}

In summary, in terms of accuracy, teacher's presence did not affect this feature very much and there was not a big difference between the two conditions concerning accuracy. In terms of fluency, participants showed greater fluency in teacher's presence and this difference was statistically significant. Concerning complexity, our alternative hypothesis was not confirmed but it is not to say that it was absolutely rejected. Considering the means, participants performed with greater complexity in teacher's presence although it was not proved statistically.

Although we discussed the results in terms of teacher's presence or absence, there might have been other factors influencing the learners' performance which were out of control.

Our findings in terms of accuracy did not follow the previous findings in that Williams (2001) found out that participants were more accurate in teacher's presence but in our study it was not the case. Also, Ortega (2005) stated that participants paid more attention to form in presence of an authentic listener and our results ran against this finding.

\section{Conclusion}

The results of this study are in line with Skehan \& Foster's (2001) proposition that 'prioritization or predisposition (or both) seem to orient performance towards one (or two) of the three areas [accuracy, fluency, and complexity] theorized to be important, with the result that the other(s) suffers.'

As came out in Brady and Bedient (2003) study, the participants in this study could complete the task better in teacher's presence. In his/her absence they felt something was missing.

Once again this study confirms the trade-off effect among the three components of learners' performance i.e. accuracy, fluency and complexity.

\section{Implications}

The findings of this study provide theoretical bases and practical considerations for those foreign language instructors who are involved in task-based language instruction and task-based testing. Meanwhile, the findings are of practical help, for syllabus designers, language testers and material developers in the field of General English and English for Specific Purposes.

\section{References}

Basturkmen, H. (2003). So what happens when the tutor walks in? Some observations on interaction in a university discussion group with and without the tutor. Journal of English for Academic Purposes, 2, 21-33.

Brady, E., \& Bedient, D. (2003). The effects of teacher presence on student performance and attitudes .WebCT IMPACT, 5th Annual WebCT User Conference.

Bygate, M. (1996). Effects of task repetition: apprising the developing language of learners. In Willis, D., \& Willis, J. (Ed.). Challenge and change in language teaching. London: Heinemann.

Elder, C \& Iwashita, N. (2005) Planning for test performance: does it make a difference? In Ellis, R. (Ed.) Planning and Task Performance in a Second Language (pp. 219- 237). Amsterdam: Benjamins.

Foster, P., \& Skehan, P. (1996) .The influence of planning time on performance in task-based learning. Studies in Second Language Acquisition, 18,299-234.

Gilabert, R. (2005). Task complexity and L2 narrative oral production. Unpublished Ph.D. dissertation, Barcelona, The University of Barcelona, Spain.

Gilabert, R. (2007). Effects of manipulating task complexity on self-repairs during L2 oral production. International Review of Applied Linguistics in Language Teaching (IRAL), 45/3, 215- 240.

Long, M.H. \& Crooks, G. (1998). Three approached to task-based syllabus design. TESOL Online, 27-56.

Ortega, L. (2005). What do learners plan? Learner-driven attention to form during pre-task planning. In R. Ellis. (Ed.), Planning and Task Performance in a Second Language (pp. 219- 237). Amsterdam: Benjamins.

Pica, T.; R. Young, and C. Doughty. 1987. The impact of interaction on comprehension. TESOL Quarterly, 21 (4): 737-58.

Rahimpour, M. (1995). Interlanguage variation and task performance. Paper presented at SLARF ' 95 Conference at Cornell University, Ithaca, New York.29th September-1st October, 1995. 
Rahimpour, M. (1997). Task complexity, task condition and variation in L2 oral discourse. Unpublished Ph.D. thesis. CLTR. The University of Queensland, Brisbane, Australia.

Rahimpour, M. (1999). 'Task complexity and variation in interlanguage'. In N. Jungheim \& P. Robinson (Eds.) Pragmatics and Pedagogy: Proceedings of The 3rd Pacific Second Language Research Forum, Vol 2 (pp.115-134) Tokyo: PacSLRF.

Rahimpour, M. (2001). The acquisition of L2 in instructed and naturalistic settings. Journal of the Faculty of Letters and Humanities. Tabriz University. 1 - 2, 9 - 33.

Rahimpour, M. (2002). Factors affecting task difficulty. Journal of the Faculty of Letters and Humanities. 9/33, 1 16.

Rahimpour, M. (2005). The impact of task types on L2 learners' performance. Paper presented at AILA 2005. University of Wisconsin. U.S.A.24-29, July2005.

Rahimpour, M. (2007) Task complexity and variation in L2 learner's oral discourse. The University of Queensland Working Papers in Linguistics, Australia.

Rahimpour, M. (2008). Implementation of task-based approaches to language teaching. Foreign Language Research, 41, Special Issue, 45 - 61.

Rahmimpour,M.(2010). Impact of task condition on L2 Learners' oral performance. Research on Foreign Languages Journal of Faculty of Letters and Humanities, 208, 13-23.

Rahimpour, M. \& Harrington, M. (1996). 'Cognitive load, task condition and language narrative discourse' Paper presented in 21st ALAA conference, University of Western Sydney, 3-6 October, 1996.

Robinson, P. (1995). Task complexity and second language narrative discourse. Language Learning 45: 283-331.

Robinson, P. (2001). 'Task complexity, task difficulty, and task production: Exploring interactions in a componential framework' Applied Linguistics 22: 27-57.

Robinson, P. (2005). Cognitive complexity and task sequencing: studies in a componential framework for second language task design. International Review of Applied Linguistics, 43, 1-32.

Robinson, P., Rahimpour, M., \& Urwin, J. (1996). ‘Taxonomizing second languagetask complexity' .Paper presented at PacSLRF' 96 Conference, Victoria University of Wellington, New Zealand. 30th Jan-2nd Feb. 1996.

Skehan, P. (1996). A framework for the implementation of task-based instruction. Applied Linguistics, 17(2), 38-62.

Skehan. P. (1998).A cognitive approach to language learning. Oxford: Oxford University Press.

Skehan, P. and Foster, P. (1999). The influence of task structure and processing conditions on narrative retellings. Language Learning, 49/1, 93 - 120.

Skehan, P. \& Foster, P. (2001). Cognition and tasks. In P. Robinson (Ed.), Cognition and second language instruction (pp.183-205). Cambridge: Cambridge University Press.

Williams, J. (2001).The effectiveness of spontaneous attention to form. System, 29,325-340.

Yule, G., Powers, M., \& Macdonald, D. (1992).the variable effects of some task-based learning procedures on L2 communicative effectiveness. Language Learning, 42(2):249-277. 
Appendix (Picture Story) Taken from Elder and Iwashita (2005)
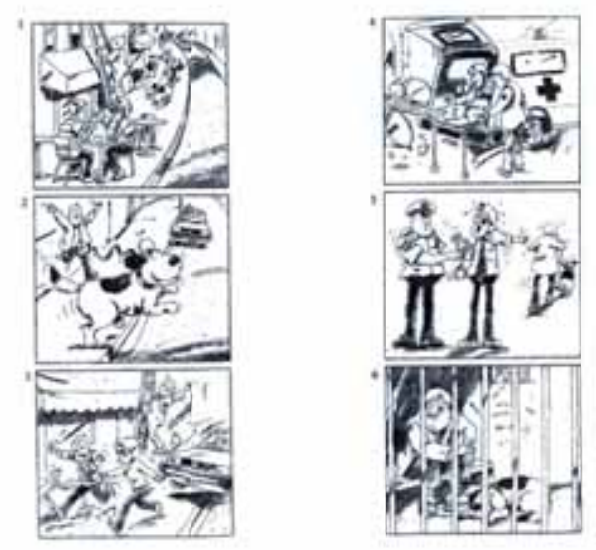

Table 1. Descriptive statistics for learners' oral performance

\begin{tabular}{|l|c|c|c|}
\hline & $\mathrm{N}$ & Mean & Std. Deviation \\
\hline Accuracy with teacher presence & 20 & 0.633 & 0.184 \\
\hline Accuracy without teacher presence & 20 & 0.665 & 0.202 \\
\hline Fluency with teacher presence & 20 & 13.46 & 7.043 \\
\hline Fluency without teacher presence & 20 & 7.857 & 2.575 \\
\hline Complexity with teacher presence & 20 & 43.729 & 4.55 \\
\hline Complexity without teacher presence & 20 & 41.713 & 3.283 \\
\hline
\end{tabular}

Table 2. Independent samples t-test for accuracy, fluency and complexity of learners' oral performance

\begin{tabular}{|c|c|c|c|c|}
\hline Measure & Sig. & T Observed & df & Sig(2-tailed) \\
\hline Accuracy & 0.587 & -0.523 & 38 & 0.604 \\
\hline Fluency & 0.012 & 3.341 & 38 & 0.003 \\
\hline Complexity & 0.218 & 1.607 & 38 & 0.116 \\
\hline
\end{tabular}

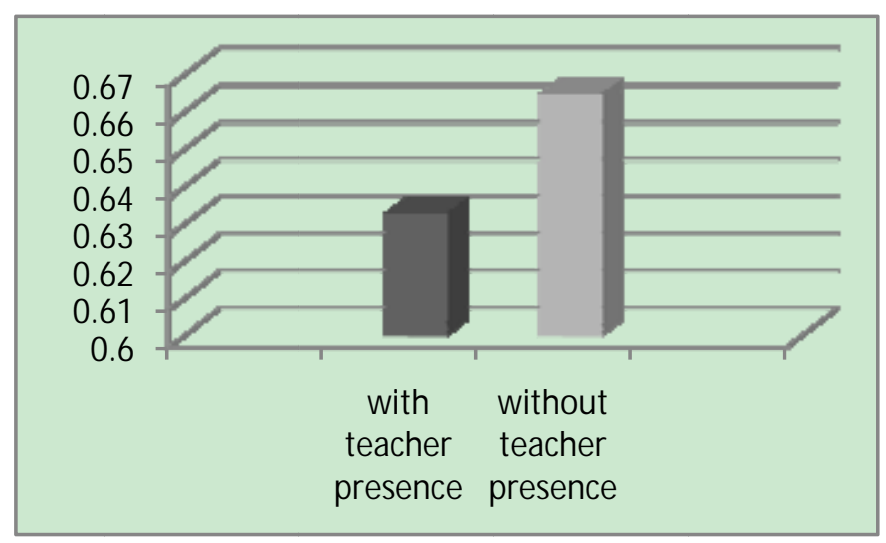

Figure 1. Mean of accuracy of L2 learners' oral performance with and without teacher presence 


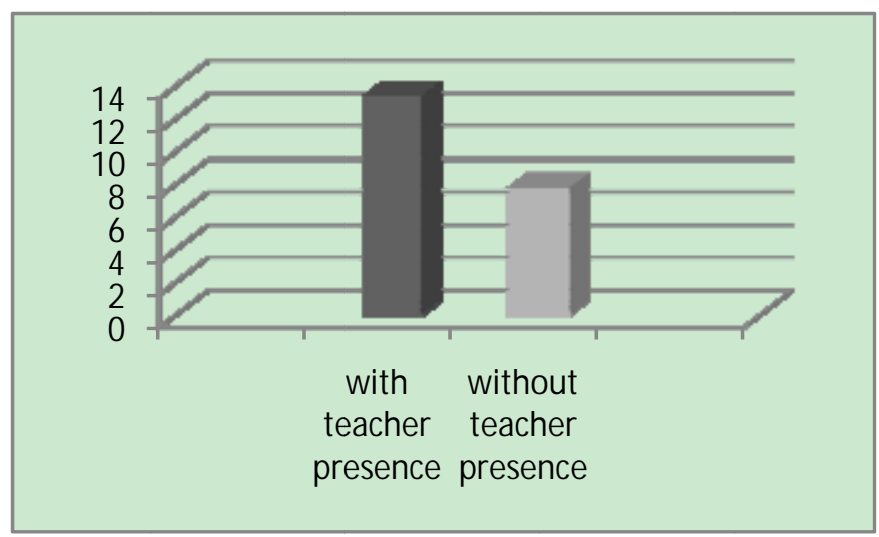

Figure 2. Mean of fluency of L2 learners' oral performance with and without teacher presence

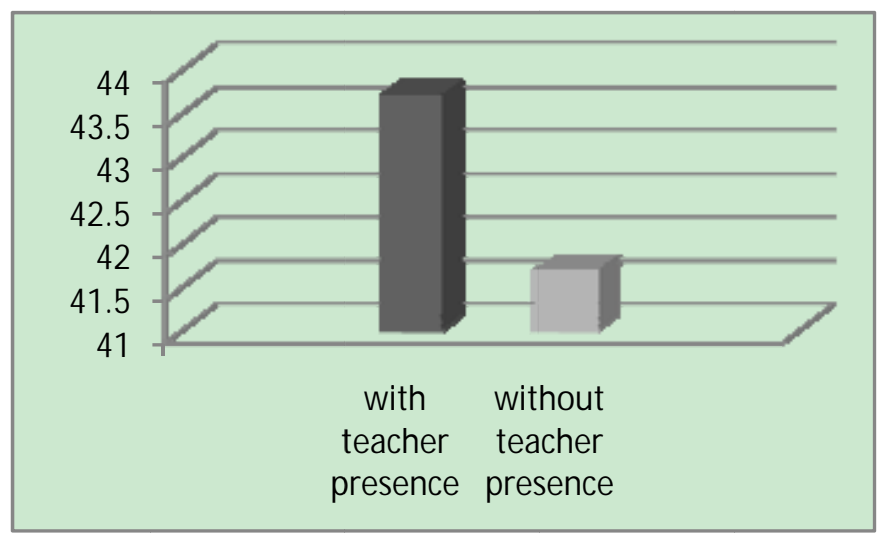

Figure 3. Mean of complexity of L2 learners' oral performance with and without teacher presence 